Article

\title{
Surfactant-Assisted Fabrication of Alumina-Doped Amorphous Silica Nanofiltration Membranes with Enhanced Water Purification Performances
}

\author{
Xianzheng Ma ${ }^{1}$, Katarzyna Janowska ${ }^{1} \mathbb{D}$, Vittorio Boffa ${ }^{1, *(\mathbb{D})}$, Debora Fabbri ${ }^{2}$, Giuliana Magnacca ${ }^{2,3}(\mathbb{D}$, \\ Paola Calza ${ }^{2}$ and Yuanzheng Yue ${ }^{1}(\mathbb{D}$ \\ 1 Department of Chemistry and Bioscience, Aalborg University, Fredrik Bajers vej 7H, 9220 Aalborg, \\ Denmark; xm@bio.aau.dk (X.M.); kaj@bio.aau.dk (K.J.); yy@bio.aau.dk (Y.Y.) \\ 2 Department of Chemistry, University of Turin, Via P. Giuria 5/7, 10125 Torino, Italy; \\ debora.fabbri@unito.it (D.F.); giuliana.magnacca@unito.it (G.M.); paola.calza@unito.it (P.C.) \\ 3 NIS Interdepartmental Center, Universitá di Torino, Via P. Giuria 7, 10125 Torino, Italy \\ * Correspondence: vb@bio.aau.dk; Tel.: +45-9940-3579
}

Received: 31 August 2019; Accepted: 20 September 2019; Published: 24 September 2019

\begin{abstract}
Surfactant-templated $5 \mathrm{~mol} \% \mathrm{Al}_{2} \mathrm{O}_{3}$-doped silica membranes nanofiltration membranes were synthesized via the sol-gel method, and afterward, were optimized, and tested with respect to the permeability and rejection rate. The disordered silica network was stabilized by doping $5 \mathrm{~mol} \%$ alumina. Tetraethyl orthosilicate and aluminum isopropoxide were used as the silica and alumina precursors, respectively. Cetyltrimethylammonium bromide (CTAB) was used not only as a pore-forming agent, but also to control the reaction rate of the aluminum isopropoxide, thus obtaining highly homogeneous materials. The results about filtration of model solutions showed that the optimized membranes are featured by both a relatively high water permeability $\left(1.1-2.3 \mathrm{~L} \cdot \mathrm{m}^{-2} \cdot \mathrm{h}^{-1} \cdot \mathrm{bar}^{-1}\right)$ and a high rejection for salts $\left(74 \%\right.$ for $\mathrm{NaCl}$, and $>95 \%$ for $\mathrm{MgSO}_{4}$ and $\mathrm{Na}_{2} \mathrm{SO}_{4}$ ) and organic pollutants (e.g., about $98 \%$ for caffeine). High rejection of divalent ions and organic molecules was also observed when a real wastewater effluent was filtered. The influence of the synthesis conditions on the membrane performance is discussed.
\end{abstract}

Keywords: sol-gel; wastewater; depollution; desalination; selectivity

\section{Introduction}

Water scarcity is one of the most pressing challenges for the human population. Moreover, the growing demand for clean water and the limited access to water resources for a large part of the global population urgently require sustainable approaches to address this problem, without compromising water access for the future generations [1,2]. Various approaches have been developed to address water depollution in an energy-efficient manner, including adsorption, filtration, electrochemistry, and photocatalysis [3]. In this context, pressure-driven membrane filtration systems, such as nanofiltration (NF), have become increasingly popular since they do not require any chemical treatment or thermal input to the treated water. NF membranes have a pore size ranging between 1 and $2 \mathrm{~nm}$. Therefore, such membranes are efficient for removing multivalent salt ions and small organic pollutants [2,4,5]. Hence, NF membranes might represent one of the possible solutions to the issues of water scarcity and water pollution. Currently, polymeric membranes dominate the NF market, because they can offer a good compromise between selectivity and water permeability. Indeed, commercial polyamide NF membranes can achieve a rejection of about $97 \%$ for divalent ion salts $\left(\mathrm{MgSO}_{4}\right)$ while maintaining a good permeability (i.e., 6.7-10.9 L $\cdot \mathrm{m}^{-2} \cdot \mathrm{h}^{-1} \cdot \mathrm{bar}^{-1}$ ) [6-8]. However, polymer membranes have a low tolerance for harsh mechanical and chemical conditions. Membrane fouling requires frequent chemical cleaning, which limits their usage and lifespan $[9,10]$. On the other hand, inorganic NF membranes 
show great potential for water desalination and detoxification, because they are easy to be cleaned and have a long service life [11,12]. Nevertheless, inorganic NF modules have low water permeability and filtering area density compared to the polymer membranes, preventing them from practical application in water filtration [13].

Surfactant-templated amorphous (i.e., non-crystalline) silica represents ideal membrane materials, due to their high pore volume and narrow pore size distribution in a range suitable for NF. Surfactants are applied as sacrificial templates to create nanopores during material consolidation and calcination, thus tailoring the porosity of the final membrane material [14]. However, amorphous silica ( $a$-silica) membranes are unstable in basic solutions [15], and in the hydrothermal environment [16,17]. Hence, this limits the perm/selectivity and the field of usage of $a$-silica membranes. The stability of the $a$-silica framework can be enhanced by doping with metal oxides. Moreover, doping can alter interfacial properties, morphology, hydrophilicity, and surface charge of the membranes $[13,14,18]$, and therefore, improve membrane performances, such as ion rejection and fouling resistance [3,18].

The stability of several metal oxide-silica compositions, such as cobalt oxide-silica, zirconium oxide-silica, and titanium oxide-silica, etc., have been studied [15,19,20]. In particular, the enhanced stability has been observed for the $\mathrm{SiO}_{2}-\mathrm{Al}_{2} \mathrm{O}_{3}$ film-based membrane [21]. The $\mathrm{Al}_{2} \mathrm{O}_{3}-\mathrm{SiO}_{2}$ system is often used for the fabrication of zeolite membranes, which are highly stable and can achieve high rejection for ions and micropollutants. However, their crystalline structure makes it difficult to reduce the thickness of the membrane layer to below $1 \mu \mathrm{m}$, thus limiting their permeability, which is usually lower than $0.1 \mathrm{~L} \cdot \mathrm{m}^{-2} \cdot \mathrm{h}^{-1} \cdot \mathrm{bar}^{-1}$ [22]. On the other hand, surfactant-templated $a$-silica consists of a long-range disordered network with an open structure, which can be synthesized via a simple sol-gel method and deposited as films with the thickness of a few hundred nanometers by dip-coating. Moreover, surfactant-templated silica possesses pores with size ranging from 1.5 to $10 \mathrm{~nm}$, while zeolites have typically pore size of $<1 \mathrm{~nm}$. Therefore, surfactant-template silica membranes typically allow for much greater water fluxes than zeolite membranes [23].

When synthesizing the binary silica-alumina films for membranes by the sol-gel method, it might be a challenge to obtain homogeneous colloids, since aluminum alkoxides have a much higher hydrolysis rate than tetraethyl orthosilicate (TEOS) [24]. A two-steps synthesis approach is often applied to obtain homogeneous sol systems when two precursors have different reactivities $[13,25,26]$. The first step is the pre-hydrolysis of the precursor with the lowest reactivity. The second step is the addition of the precursor with the highest reactivity. Previous studies have shown that surfactant molecules can also reduce the hydrolysis and condensation rate of alkoxide precursors, as they can interact with the metal center in the forming particles and limiting the reactions rates $[25,26]$. Hence, the surfactant was introduced into the reaction mixture after the pre-hydrolysis of TEOS, but before adding the aluminum alkoxide. Therefore, the surfactant had a dual function: (i) To control the hydrolysis and the condensation rate of precursors during synthesis, and (ii) to control the pore structure, as sacrificial pore-forming agent during material consolidation and calcination. Indeed, precipitation of $\mathrm{Al}_{2} \mathrm{O}_{3}$ from the sol was always observed when the surfactant was added after the second step. Nevertheless, depending on the synthesis conditions and sol composition, phase separation might occur in the final membrane material when the molar ratio of the alumina reach to $10 \%$ [27-29].

In this work, the $5 \mathrm{~mol} \% \mathrm{Al}_{2} \mathrm{O}_{3}$-doped silica membranes $\mathrm{NF}$ membranes were fabricated by optimizing the concentration of the coating sol and the molar ratio of surfactant/oxide (S/O). The impact of these fabrication parameters on membrane selectivity and permeability was investigated by performing filtration tests with model solutions. Then, the optimized membranes were tested regarding their ability to retain ions and pollutants in a real wastewater sample. 


\section{Experimental}

\subsection{Sol-Synthesis and Membrane Fabrication}

The fabrication procedure of our $5 \mathrm{~mol} \% \mathrm{Al}_{2} \mathrm{O}_{3}$-doped silica membranes is depicted in Figure 1. A two-steps approach was applied for the sol synthesis. The first step of synthesis was the hydrolysis of TEOS, which was achieved by letting to react a mixture of TEOS (98\%, Sigma Aldrich, St. Louis, MO, USA), ethanol (99.9\%, VWR Chemicals, Radnor, PA, USA), distilled water, and nitric acid (69\%, Sigma Aldrich, St. Louis, MO), with a molar ratio of 1:4:2.5:0.04, at $60^{\circ} \mathrm{C}$ for $3 \mathrm{~h}$. Then, in the second step of the synthesis, CTAB (99\%, Sigma Aldrich, St. Louis, MO, USA) was added to the pre-hydrolyzed TEOS solution to achieve the desired CTAB: $\left(\mathrm{SiO}_{2}+\mathrm{Al}_{2} \mathrm{O}_{3}\right)$ molar ratio. After the complete dissolution of CTAB, aluminum isopropoxide (AIP) (98\%, Sigma Aldrich, St. Louis, MO, USA) was directly added to the mixture to obtain a $5 \mathrm{~mol} \% \mathrm{Al}_{2} \mathrm{O}_{3}$ concentration in the final consolidated membrane material. The mixture was continuously stirred at $60{ }^{\circ} \mathrm{C}$ until all the AIP was dissolved and a transparent yellowish solution was obtained (the reaction times are summarized in Table 1).

Sols were diluted by 1:11, 1:15, and 1:20 volume ratios with ethanol and subsequently filtered with $0.2 \mu \mathrm{m}$ syringe filter (Minisart RC, $25 \mathrm{~mm}$, Sigma Aldrich, St. Louis, MO, USA) to remove dust particles and impurities before the coating. The membranes were coated on commercial $\alpha$-alumina tubular support with a $\gamma$-alumina intermedia layer $(250 \times 10 \times 7 \mathrm{~mm}(\mathrm{~L} \times \mathrm{OD} \times \mathrm{ID})$, Pervatech B.V., Rijssen, The Netherlands). The membranes were fabricated by dip-coating of the alumina-doped silica sols onto the supporting substrates. Specifically, the inside of the supports was coated vertical by a lab-made device at a dipping/withdrawing rate of $<2.5 \mathrm{~cm} / \mathrm{min}$. After drying at room temperature for $24 \mathrm{~h}$, the membranes were calcined at $450{ }^{\circ} \mathrm{C}$ for $2 \mathrm{~h}$ at the heating and cooling rate of $2{ }^{\circ} \mathrm{C} / \mathrm{min}$.

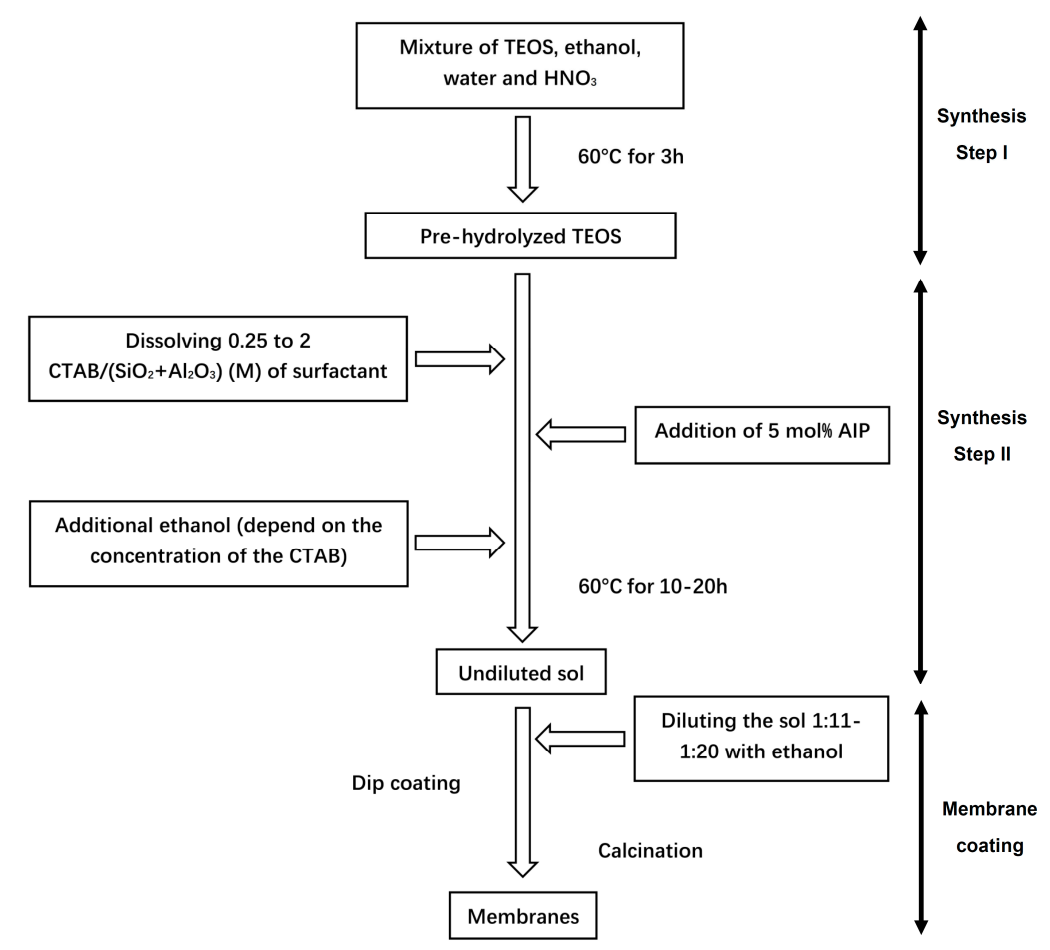

Figure 1. Synthesis process of the membranes with different cetyltrimethylammonium bromide (CTAB) concentration.

The corresponding powdered samples were obtained by filtering the rest of coating sol through a $0.2 \mu \mathrm{m}$ syringe filter after dilution with ethanol $(1: 1 \mathrm{~V} / \mathrm{V})$ and dried in Petri-dishes. The membrane materials were calcined by following the same temperature ramp of the supported membranes. After the calcination, the membrane materials were crushed in a mortar and kept for further analysis. 
Table 1. Fabrication parameters of the membrane samples synthesized in this work.

\begin{tabular}{|c|c|c|c|c|}
\hline $\mathrm{S} / \mathrm{O}^{\#}$ & Reaction Time (h) & TEOS:Ethanol (mol:mol) & $\mathrm{Al}_{2} \mathrm{O}_{3}: \mathrm{SiO}_{2}(\mathrm{~mol} \%)$ & $\begin{array}{c}\mathrm{Al}_{2} \mathrm{O}_{3}+\mathrm{SiO}_{2} \\
\text { Concentration }{ }^{\S}\left(\mathrm{g} \cdot \mathrm{L}^{-1}\right)\end{array}$ \\
\hline \multicolumn{5}{|c|}{ Membrane samples with different sol dilutions } \\
\hline 0.25 & 15 & $1: 4$ & $5 \%$ & 11.8 \\
\hline 0.25 & 15 & $1: 4$ & $5 \%$ & 8.7 \\
\hline 0.25 & 10 & $1: 4$ & $5 \%$ & 6.5 \\
\hline \multicolumn{5}{|c|}{ Membrane samples with different CTAB concentrations } \\
\hline 0.25 & 10 & $1: 4$ & $5 \%$ & 6.5 \\
\hline 0.5 & 10 & $1: 4$ & $5 \%$ & 6.5 \\
\hline 1 & 10 & $1: 8^{*}$ & $5 \%$ & 6.5 \\
\hline 2 & 20 & $1: 12$ * & $5 \%$ & 6.5 \\
\hline 4 & 40 & $1: 32$ * & $5 \%$ & 6.5 \\
\hline
\end{tabular}

\# $\mathrm{S} / \mathrm{O}=$ surfactant/oxide ratio $=\mathrm{CTAB} /\left(\mathrm{SiO}_{2}+\mathrm{Al}_{2} \mathrm{O}_{3}\right)(\mathrm{mol} / \mathrm{mol}) ;{ }^{*}$ additional ethanol was added to dissolve the $\mathrm{CTAB}$;

$\S$ Sols were diluted before coating to achieve the oxide $\left(\mathrm{SiO}_{2}+\mathrm{Al}_{2} \mathrm{O}_{3}\right)$ concentration reported in this table.

\subsection{Membrane Characterization}

The pore structure of the membrane materials was investigated by nitrogen adsorption at liquid-nitrogen boiling point on a gas volumetric apparatus ASAP 2020 (Micromeritics, Norcross, GA, USA), after outgassing at $300{ }^{\circ} \mathrm{C}$ in the vacuum (residual pressure $10^{-2} \mathrm{mbar}$ ) to avoid undesired interferences of gaseous products from materials during the gas-volumetric determinations. Specific surface areas were determined using the Langmuir model. Pore volumes and pore size distributions were calculated by using the density functional theory (DFT) method to examine simultaneously both micro and mesoporosity of the samples [30]. The morphology of the membrane cross-section and surface was investigated by SEM analysis using a EVO 50 XVP microscope (Zeiss, Köln, Germany) with $\mathrm{LaB}_{6}$ source. The samples were mounted on metallic stubs with double-sided conductive tape and ion coated with a gold layer (thickness $\sim 25 \mathrm{~nm}$ ) by a sputter coater (Baltec SCD 050, Pfäffikon, Switzerland) for $60 \mathrm{~s}$ under vacuum at a current intensity of $60 \mathrm{~mA}$ to avoid any charging effect.

\subsection{Filtration Tests}

The cross-flow setup for the filtration experiment is described in detail elsewhere [31]. Water permeability was measured under four different operating pressure ranges from 5 to 7 bar. The following reagents were dissolved in deionized water to prepare model solutions for the filtration test: $\mathrm{NaCl}$ (99.0\%, Chemsolute, Roskilde, Denmark), $\mathrm{MgSO}_{4} \cdot 7 \mathrm{H}_{2} \mathrm{O}$ (99.0\%, Acros Organics, Geel, Belgium), $\mathrm{Na}_{2} \mathrm{SO}_{4},(99.0 \%$, Sigma Aldrich, St. Louis, MO, USA), and caffeine (Sigma Aldrich, St. Louis, MO, USA). Salt solutions with an ionic strength of $0.01 \mathrm{M}$ and a caffeine solution $(10 \mathrm{ppm})$ were prepared as feed for selectivity measurements. The selectivity tests were operated at 7 bar, the salt rejection was determined by measuring the electrical conductivity of the feeding and permeate water by using a conductivity meter Seven Multi (Mettler Toledo, Columbus, OH, USA). Caffeine concentration was determined by HPLC over a Dionex ASI-100 chromatograph with a Phenomenex Luna C18 column, with diameter, length, and pore size of $4.60 \mathrm{~mm}, 250 \mathrm{~mm}$, and $5 \mu \mathrm{m}$, respectively. The mobile phase was deionized water (buffered with $0.025 \mathrm{M} \mathrm{KH}_{2} \mathrm{PO}_{4}$ ) and acetonitrile (ACN) with a proportion ACN/buffer of 20/80, delivered at a flow rate of $1.2 \mathrm{~mL} \cdot \mathrm{min}^{-1}$.

In order to test the performance of membranes towards the inorganic ions and organic pollutants, we analyzed the wastewater effluent and the permeate for the presence of some ions $\left(\mathrm{Cl}^{-}, \mathrm{NO}_{3}{ }^{-}, \mathrm{SO}_{4}{ }^{2-}, \mathrm{Na}^{+}, \mathrm{K}^{+}, \mathrm{Mg}^{2+}, \mathrm{Ca}^{2+}\right)$ and for the presence of contaminants of emerging concern (in particular imidacloprid (IMI), ciprofloxacin (CPX), carbamazepine (CBZ), 1,2,3-benzotriazole (BZT) 5-methyl-1H-benzotriazole (MBZT). The content of total organic carbon (TOC) and total carbon (TC) was evaluated before and after the filtration step. The concentration of these target parameters was determined according to the procedures, which are described in detail in the Supplementary Materials (MS-MS conditions are reported in Table S1). 


\section{Results and Discussion}

\subsection{Impact of CTAB Concentration on Membrane Porosity}

The pore structure of the membrane materials with five different $\mathrm{CTAB}$ concentrations $(\mathrm{S} / \mathrm{O}=0.25$, $0.5,1.0,2.0$, and 4.0 ) was determined by low-temperature $\mathrm{N}_{2}$ adsorption. Despite the different CTAB concentrations, all the samples have similar adsorption isotherms and pore size distributions, as shown in Figure 2. Most of the adsorption occurs at a nitrogen relative pressure smaller than 0.1 (type I isotherms, according to the IUPAC classification, which is typical of microporous materials [32]). As a consequence, the pore size of the membrane materials ranges from 0.5 to $2.5 \mathrm{~nm}$. This pore size distribution is consistent with the use of CTAB as the pore-forming agent. The relation between the CTAB concentration and specific surface area (SSA) of the membrane materials is plotted in Figure 3. At first, SSA increases with increasing CTAB concentration. SSA reaches a maximum at $732 \mathrm{~m}^{2} \cdot \mathrm{g}^{-1}$ when the surfactant/oxide molar ratio $\left(\mathrm{S} / \mathrm{O}=\mathrm{CTAB} /\left(\mathrm{SiO}_{2}+\mathrm{Al}_{2} \mathrm{O}_{3}\right)\right)$ is 1 . Any further increase of CTAB concentration results in a reduction of the specific surface area, which may be caused by the collapse of the pore structure when a high amount of surfactant is burned out during calcination.
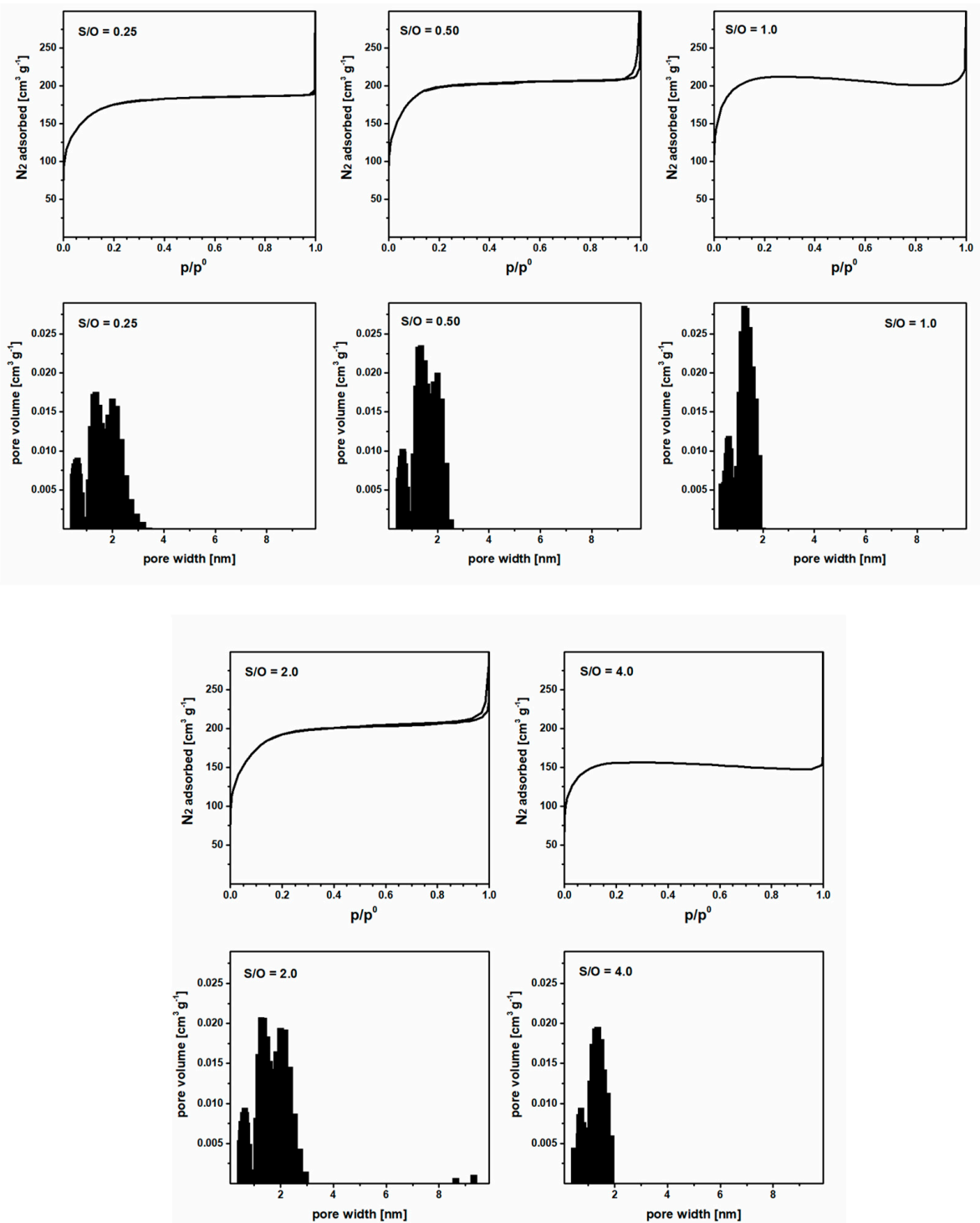

Figure 2. Adsorption isotherms and pore size distributions of the membrane materials ( $5 \mathrm{~mol} \%$ $\mathrm{Al}_{2} \mathrm{O}_{3}$-doped silica) synthesized by the sol-gel method with different surfactant/oxide molar ratio (S/O) in the reaction mixture. 


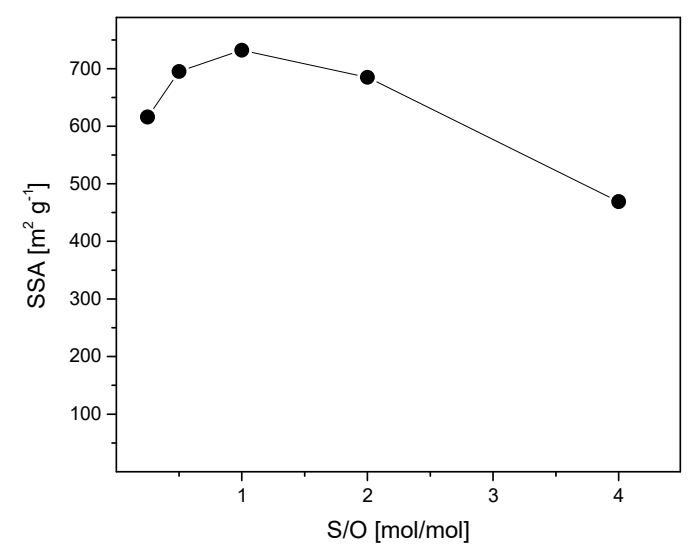

Figure 3. Specific surface area (SSA) of the membrane materials $\left(5 \% \mathrm{Al}_{2} \mathrm{O}_{3}\right.$-doped $a$-silica) as a function of the surfactant/oxide molar ratio $(\mathrm{S} / \mathrm{O})$ in the reaction mixture.

\subsection{Concentration of the Coating Sol}

The membrane materials were deposited on commercial membrane tubes by dip-coating. Different dilutions were used and Table 1 summarizes the oxide $\left(\mathrm{SiO}_{2}+\mathrm{Al}_{2} \mathrm{O}_{3}\right)$ concentrations of the final coating sols. Figure 4 shows the SEM image of a membrane obtained from a sol with $\mathrm{S} / \mathrm{O}=0.25$ and oxides $\left(\mathrm{SiO}_{2}+\mathrm{Al}_{2} \mathrm{O}_{3}\right)$ concentration of $11.8 \mathrm{~g} \cdot \mathrm{L}^{-1}$. The micrograph shows a continuous membrane layer covering the multi-layered alumina support. Form the picture, the thickness of the membrane is estimated to be around about $590 \mathrm{~nm}$. Therefore, we attempted to reduce the membrane thickness and increase membrane permeability by dilution of the coating sol. Two new membranes were prepared by reducing the oxide concentration in the sol from 11.8 to 8.7 and $6.5 \mathrm{~g} \cdot \mathrm{L}^{-1}$ while S/O was kept constant to 0.25 .

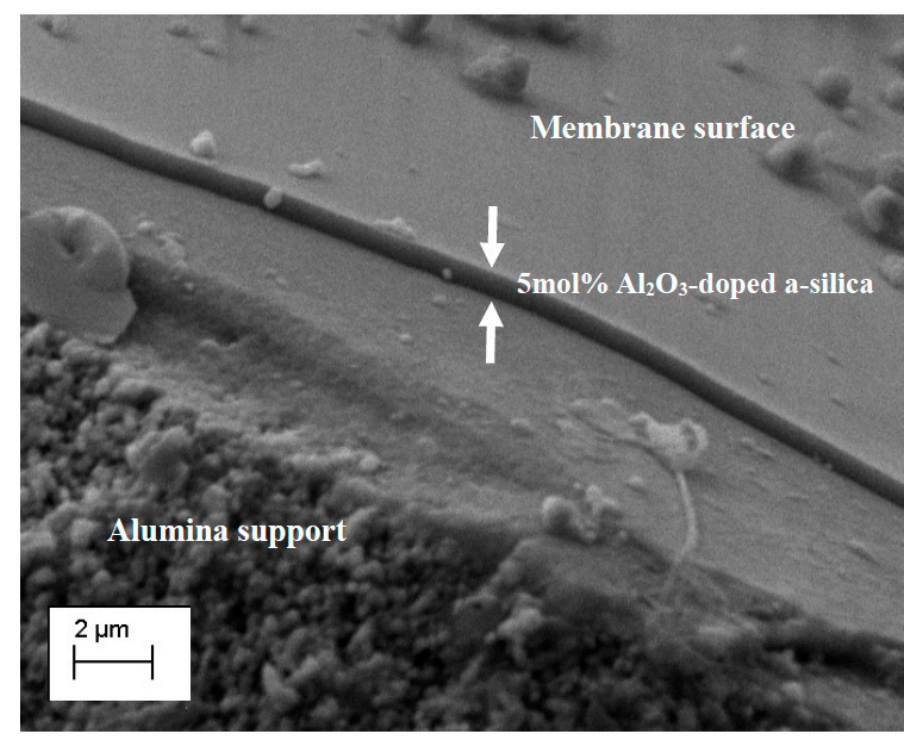

Figure 4. Cross-sectional SEM micrograph of the membrane obtained by coating a $5 \mathrm{~mol} \% \mathrm{Al}_{2} \mathrm{O}_{3}$-doped silica sol with a surfactant/oxide ration $(\mathrm{S} / \mathrm{O})$ of 0.25 and an oxide $\left(\mathrm{SiO}_{2}+\mathrm{Al}_{2} \mathrm{O}_{3}\right)$ concentration of $11.8 \mathrm{~g} \cdot \mathrm{L}^{-1}$. White arrows indicate the $5 \mathrm{~mol} \% \mathrm{Al}_{2} \mathrm{O}_{3}$-doped silica layer.

SEM images of the membrane cross-section were taken to compare the thickness of the membranes with different sol concentrations. The relation between the membrane thickness and the sol dilution is reported in Figure $5 \mathrm{a}$. The thickness of the $5 \mathrm{~mol} \% \mathrm{Al}_{2} \mathrm{O}_{3}$-doped silica membrane layer decreases by reducing the oxide concentration in the coating sol: From $560 \mathrm{~nm}$ to $96 \mathrm{~nm}$ when the sol oxide concentration was reduced from 11.8 to $6.5 \mathrm{~g} \cdot \mathrm{L}^{-1}$. Surprisingly, the difference in membrane thickness 
did not reflect in a large variation of the water permeability of the three membranes, as shown in Figure 5a. Indeed, when the oxide concentration in the sol decreases from 11.8 to $6.5 \mathrm{~g} \cdot \mathrm{L}^{-1}$ the average water permeability has only changed slightly: From 0.64 to $0.68 \mathrm{~L} \cdot \mathrm{m}^{-2} \cdot \mathrm{h}^{-1} \cdot \mathrm{bar}^{-1}$, that is, the change of the water permeability is negligible when compared to the decrease of the membrane thickness. This may be caused by the infiltration of the sol particles into the porous intermedia layer during the coating, resulting in a much thicker $5 \mathrm{~mol} \% \mathrm{Al}_{2} \mathrm{O}_{3}$-doped silica layer than that observed in the SEM images.
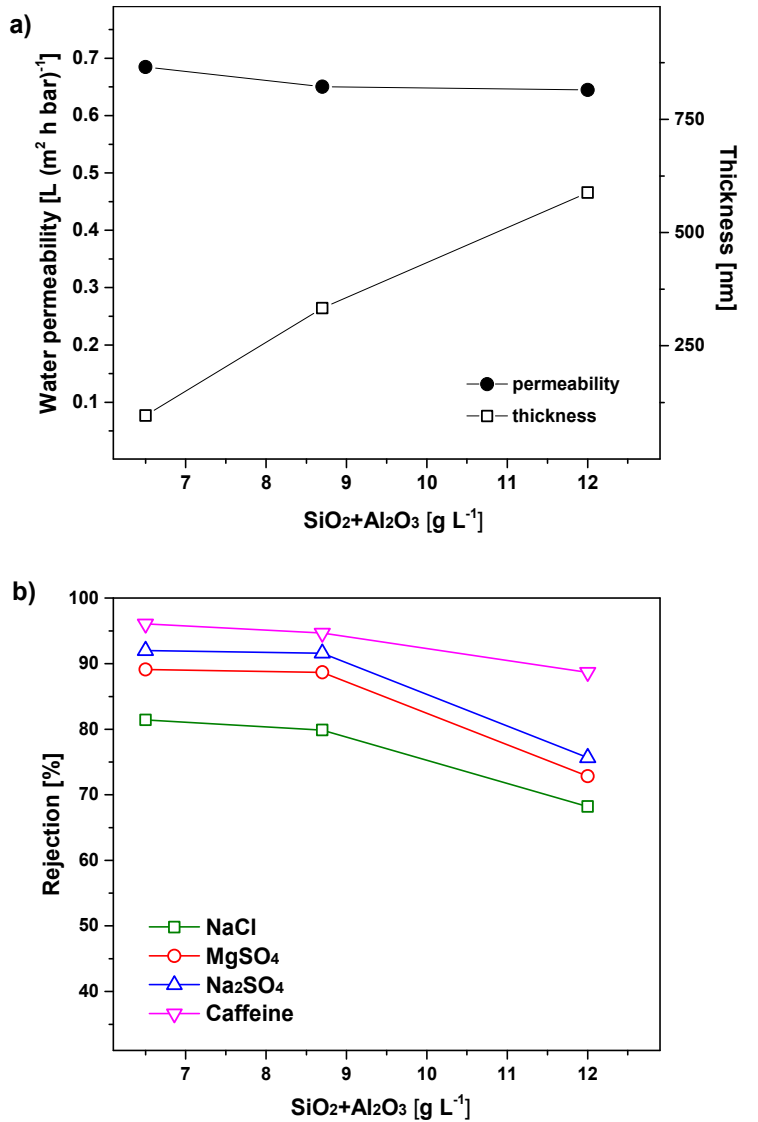

Figure 5. (a) Water permeability and thickness of $5 \mathrm{~mol} \% \mathrm{Al}_{2} \mathrm{O}_{3}$-doped silica membranes as a function of the $\mathrm{SiO}_{2}+\mathrm{Al}_{2} \mathrm{O}_{3}$ concentration in the coating sol. (b) Membrane rejection for inorganic salts and caffeine as a function of the $\mathrm{SiO}_{2}+\mathrm{Al}_{2} \mathrm{O}_{3}$ concentration in the coating sol.

The rejection of the membranes to inorganic salts and caffeine (as a model micropollutant) is shown in Figure 5b. Rejection values of the three membranes are consistent with NF membrane layers. Indeed, the three membranes show good rejection for salts of monovalent ions (68-81\% for $\mathrm{NaCl})$ and high rejection towards salts of divalent ions (73-89\% for $\mathrm{MgSO}_{4}$ and $76-92 \%$ for $\mathrm{Na}_{2} \mathrm{SO}_{4}$ ), and even higher rejection for caffeine (89-96\%). In general, the membranes ionic rejection depends on the size and the charge of the hydrated ions. For non-charged species such as caffeine, the rejection mechanism is mainly attributed to the steric exclusion. These results indicate that the three membranes consist of NF layers with a really small or negligible defect density. Counterintuitively, the rejection of ions and caffeine have an increasing trend with the decrease of the membrane thickness. For instance, the rejection for $\mathrm{NaCl}$ is increased from $68.2 \%$ to $81.4 \%$ when the oxide concentration in the coating sol decreases from 11.8 to $6.5 \mathrm{~g} \cdot \mathrm{L}^{-1}$. A possible explanation could be that thicker films have a higher chance of defect formation during drying [33], as all the membranes have the same composition and have similar pore structure. This result shows that dilution of the coating sol could improve the selectivity 
without sacrificing the membrane permeability. Therefore, we decided to prepare the membranes by using the coating sol with a rather low oxides concentration $\left(6.5 \mathrm{~g} \cdot \mathrm{L}^{-1}\right)$ in the rest of the study.

\subsection{Optimization of the $S / O$ Ratio}

Figure 6a illustrates the relationship between the water permeability of the membranes and the surfactant/oxides ratio $(\mathrm{S} / \mathrm{O}=0.25,0.5,1.0,2.0$, and 4.0$)$. A dramatic increase of the water flux is observed when $\mathrm{S} / \mathrm{O}$ is increased from 0.25 to 2.0. In this $\mathrm{S} / \mathrm{O}$ range, the permeability increases rapidly from 0.68 to $2.3 \mathrm{~L} \cdot \mathrm{m}^{-2} \cdot \mathrm{h}^{-1} \cdot \mathrm{bar}^{-1}$. However, a further increase of the surfactant concentration ( $\mathrm{S} / \mathrm{O}$ from 2.0 to 4.0 ) results in a reduced permeability $\left(1.9 \mathrm{~L} \cdot \mathrm{m}^{-2} \cdot \mathrm{h}^{-1} \cdot \mathrm{bar}^{-1}\right)$. The initial rise of the permeability for increased S/O ratios may arise from increased pore interconnectivity. However, when the concentration of surfactant is fourfold higher than the oxide materials, pore walls might collapse during calcination.

The rejections of these membranes for inorganic salts and caffeine are depicted in Figure $6 \mathrm{~b}$. The rejection for $\mathrm{NaCl}$ decreases from $81 \%$ to $59 \%$ when the surfactant concentration $(\mathrm{S} / \mathrm{O})$ increases from 0.25 to 4.0. On the contrary, the rejections for $\mathrm{MgSO}_{4}, \mathrm{Na}_{2} \mathrm{SO}_{4}$, and caffeine reach a maximum $(95 \%, 98 \%$, and $98 \%$, respectively) for the membrane prepared from a sol with $\mathrm{S} / \mathrm{O}$ of 0.50 . The increase of membrane rejection with increasing $\mathrm{S} / \mathrm{O}$ from 0.25 to 0.50 could be due to the fact that surfactant molecules contribute to reduce capillary stresses during the drying of the membrane films, thereby reducing the probability of defect formation [34]. However, when further increasing the surfactant concentrations in the coating sols, the rejection decreases for the tested three types of ions and caffeine. This trend might be ascribed to the formation of some defects in the membrane films due to the high relative mass loss and gas product development during the calcination step.

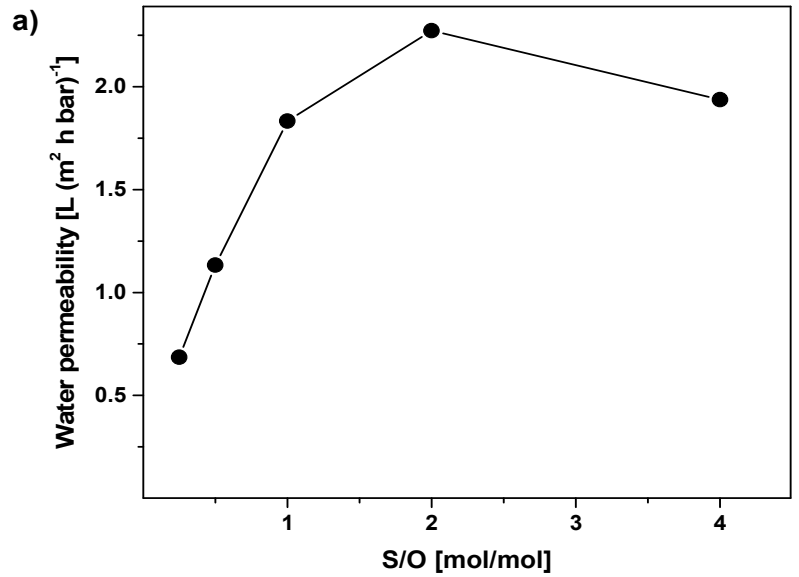

b)

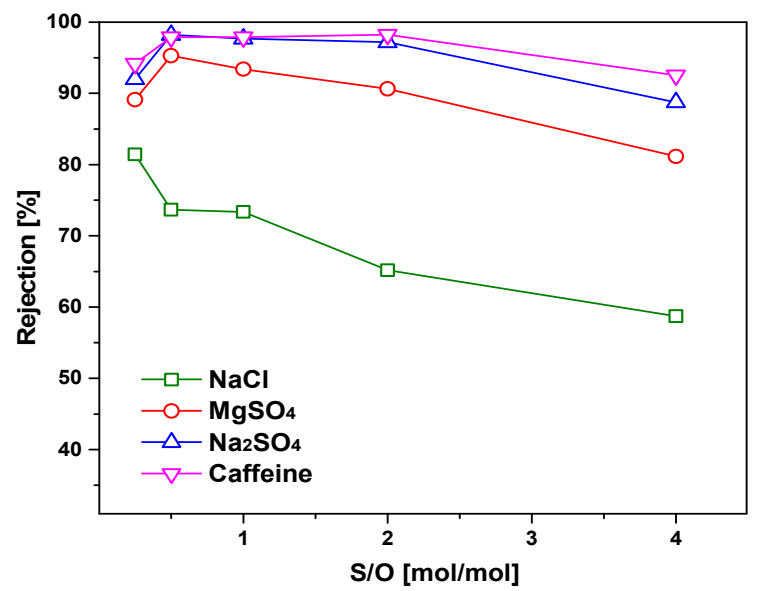

Figure 6. (a) Water permeability and (b) rejection to salt and caffeine of the $5 \mathrm{~mol} \% \mathrm{Al}_{2} \mathrm{O}_{3}$-doped silica membranes as a function of the surfactant/oxides $(\mathrm{S} / \mathrm{O})$ ratio in the coating sols. 
As expected, the effect of $\mathrm{S} / \mathrm{O}$ on the membrane rejection is not as strong as what we observed for the membrane permeability. Indeed, as shown in Figures 2 and 3, the surfactant concentration has little effect on the pore size distribution, and thus on the membrane selectivity. However, it has a great impact on the specific surface area of the material, and therefore, on the membrane permeability. In detail, the membrane with $\mathrm{S} / \mathrm{O}=2.0$ has the highest permeability, while the membrane with $\mathrm{S} / \mathrm{O}=0.5$ exhibits the best selectivity. These two membranes present selectivity close to those of zeolite membranes [35], but water permeability at least one order of magnitude higher. Therefore, they were selected as optimized membranes for filtering the effluent of the wastewater treatment plant.

\subsection{Filtration of A Wastewater Treatment Plant Effluent}

Figure 7 shows the wastewater sample before filtration and the permeates collected after the wastewater was filtered through the membranes with $\mathrm{S} / \mathrm{O}=0.50$ and 2.0. The effluent water presents a slightly yellowish color and some turbidity. On the contrary, the permeate water from both membranes is colorless and clear. This picture shows that the membranes have the ability to remove colloids and colored compounds (as humic substances) in the wastewater. As a result of the accumulation of these substances on the membrane surface, the permeability of the two membranes after $2 \mathrm{~h}$ of filtration was reduced to 0.16 and $0.32 \mathrm{~L} \cdot \mathrm{m}^{-2} \cdot \mathrm{h}^{-1} \cdot \mathrm{bar}^{-1}$ for the membranes with $\mathrm{S} / \mathrm{O}=0.50$ and $\mathrm{S} / \mathrm{O}=2.0$, respectively.

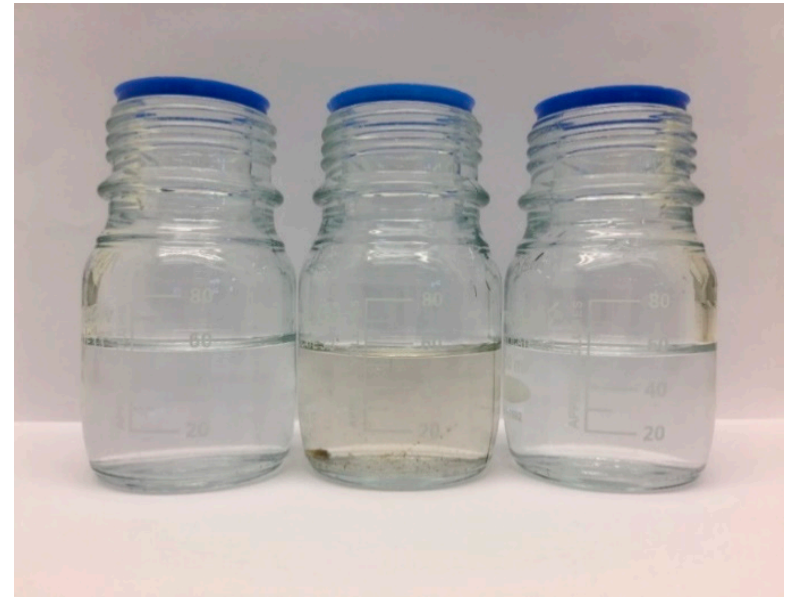

Figure 7. Samples of wastewater treatment plant effluent (middle), permeate of the membrane with surfactant/oxide ratio $(\mathrm{S} / \mathrm{O})=0.5$ (left), and permeate of the membrane with $\mathrm{S} / \mathrm{O}=2.0$ (right).

Table 2 lists the concentration of inorganic ions and selected micropollutants in the wastewater sample and in the permeates of the two membranes. In general, the two membranes have a similar selectivity. The specific selectivity for ions and total organic carbon (TOC) of the two membranes is plotted in Figure 8. TOC is also reduced by about $85 \%$. Both membranes present a high rejection of organic pollutants. The concentration of imidacloprid (IMI) and 1,2,3-benzotriazole (BZT) were become undetectable after the filtration, while the concentrations of carbamazepine (CBZ) and 5-methyl-1H-benzotriazole (MBZT) were reduced by more than $95 \%$. The two membranes show a high ability to remove inorganic ions. The highest rejection was observed for divalent ions as $\mathrm{Mg}^{2+}$ and $\mathrm{Ca}^{2+}, \mathrm{SO}_{4}{ }^{2-}$, and carbonates, which are likely the most representative species of inorganic carbon (IC) in these samples. In general, the rejection of monovalent ions is lower than the rejection of divalent ions, which is not necessarily a disadvantage, as many applications do not require to remove these ions and the permeation can result in a reduced trans-membrane osmotic pressure. 
Table 2. Concentration of ions and micropollutants in the wastewater sample as received and after the filtration over the membranes prepared from sols with $\mathrm{S} / \mathrm{O}=0.50$ (Permeate 0.5 ) and $\mathrm{S} / \mathrm{O}=2.0$. (Permeate 2). The data for imidacloprid (IMI), carbamazepine (CBZ), 1,2,3-benzotriazole (BZT), and 5-methyl-1H-benzotriazole (MBZT) take into account a preconcentration factor of 200 on solid phase extraction (SPE).

\begin{tabular}{cccc}
\hline & $\begin{array}{c}\text { Wastewater Treatment } \\
\text { Plan Effluent }(\mathbf{p p m})\end{array}$ & $\begin{array}{c}\text { Permeate S/O = 0.5 } \\
(\mathbf{p p m})\end{array}$ & Permeate S/O = 2 (ppm) \\
\hline $\mathrm{Cl}^{-}$ & 92.1 & 67.5 & 56.5 \\
$\mathrm{NO}_{3}{ }^{-}$ & 20.2 & 12.0 & 14.4 \\
$\mathrm{SO}_{4}{ }^{-}$ & 40.9 & 15.7 & 13.0 \\
$\mathrm{Na}^{+}$ & 103 & 16.0 & 14.4 \\
$\mathrm{~K}^{+}$ & 27.2 & 2.95 & 3.53 \\
$\mathrm{Mg}^{2+}$ & 7.1 & 0.11 & 0.11 \\
$\mathrm{Ca}^{2+}$ & 92 & 0.77 & 0.82 \\
$\mathrm{TOC}$ (total organic carbon) & 8.51 & 1.26 & 1.31 \\
$\mathrm{TC}$ (total carbon) & 69.0 & 6.59 & 6.97 \\
$\mathrm{IMI}$ & $3 \times 10^{-5}$ & - & - \\
$\mathrm{CBZ}$ & $8.4 \times 10^{-4}$ & $2.3 \times 10^{-5}$ & $3.4 \times 10^{-5}$ \\
$\mathrm{BZT}$ & $1.7 \times 10^{-4}$ & - & - \\
$\mathrm{MBZT}$ & $1.7 \times 10^{-3}$ & $1.5 \times 10^{-5}$ & $2.0 \times 10^{-5}$ \\
\hline
\end{tabular}

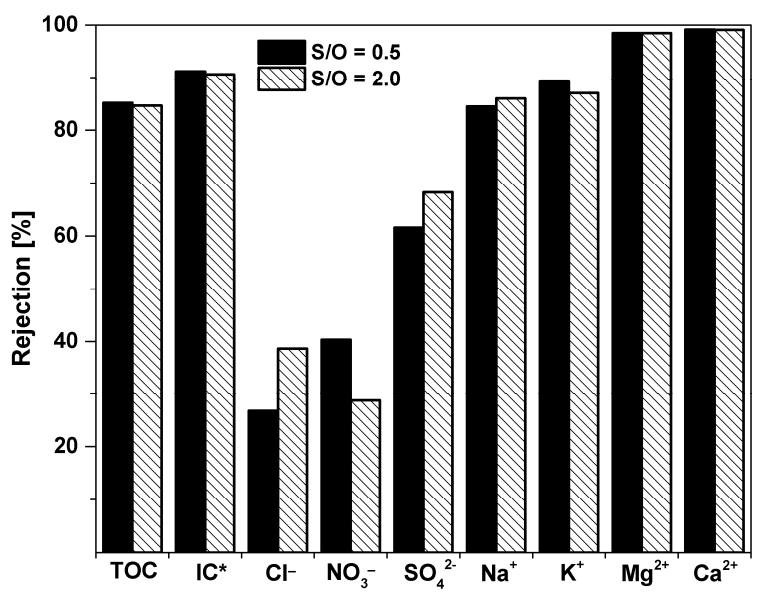

Figure 8. The rejection of the ions, micropollutants, and organic carbon contained in wastewater for the optimized membranes. IC ${ }^{*}$ (inorganic carbon) $=$ TC - TOC.

\section{Conclusions}

In this study, we presented a simple method for the fabrication of the $5 \mathrm{~mol} \% \mathrm{Al}_{2} \mathrm{O}_{3}$-doped silica NF membranes. A surfactant, namely CTAB, was added during the sol-gel synthesis of the membrane material to reduce the hydrolysis and condensation rate of the aluminum alkoxide precursor, thus obtaining a homogeneous amorphous oxide network, and to act as pore-forming agent (template) during the calcination step. NF membranes were obtained by a single coating by dipping commercial alumina support in the $\mathrm{Al}_{2} \mathrm{O}_{3}$-doped silica sols. This approach may provide good bases for further development and fabrication of other metal oxide-doped silica membranes.

We were able to reduce the thickness of the membranes down to $96 \mathrm{~nm}$. However, membrane thickness, as observed at SEM, had a slight impact on the water permeability of our membranes, probably due to the penetration of the polymeric silica sol into the pores of the membrane support. The increase of the CTAB concentration in the coating sol has little impact on the pore size of the consolidated material, and therefore on the selectivity of the membrane layer. On the contrary, membrane permeability was greatly enhanced by the optimization of the surfactant concentration. During the filtration tests, the highest water permeability $\left(2.3 \mathrm{~L} \cdot \mathrm{m}^{-2} \cdot \mathrm{h}^{-1} \cdot \mathrm{bar}^{-1}\right)$ was achieved by the membranes prepared from the sol with $\mathrm{S} / \mathrm{O}=2.0$, while the highest rejection values were obtained for the membrane coated from the sol with $\mathrm{S} / \mathrm{O}=0.50$. All the membranes presented in this work have rather high rejection towards caffeine. 
Filtration of an effluent from a wastewater treatment plant indicates that the optimized membranes are capable of removing water-hardness ions such as $\mathrm{Mg}^{2+}$ and $\mathrm{Ca}^{2+}$, micropollutants and colored organic matter from real water systems. Thus, the membranes developed in the present study have high potential to be applied in tertiary treatments of wastewater or in the treatment of brackish water.

Supplementary Materials: The following are available online at http://www.mdpi.com/2079-4991/9/10/1368/s1, Table S1: MS-MS conditions of organic pollutants detected in the sample (DP-declustering potential, EP extensions potential, CE collision energy).

Author Contributions: Conceptualization, X.M., V.B. and Y.Y.; methodology, X.M., D.F., G.M. and P.C.; formal analysis, X.M., K.J. and D.F.; investigation X.M. and K.J.; resources, V.B. Y.Y. and P.C.; writing original draft, X.M.; writing-review and editing, V.B. Y.Y. and P.C.; supervision, V.B. Y.Y. and P.C.; funding acquisition, V.B. and P.C.

Funding: This work is part of a project that has received funding from the European Union's Horizon 2020 research and innovation programme under the Marie Skłodowska-Curie Grant Agreement No 765860 (AQUAlity). The authors gratefully acknowledge also financial support from the European Union project "Project $\hat{O}^{\text {" }}$ (H2020-CIRC-2017TwoStage, Grant Agreement n. 776816). Moreover, the author wish to thanks Marta Anna Nierychlo for her support with the wastewater sample.

Acknowledgments: The authors wish to thank the European Commission for funding.

Conflicts of Interest: The authors declare no conflict of interest.

\section{References}

1. Shrivastava, A.; Rosenberg, S.; Peery, M. Energy efficiency breakdown of reverse osmosis and its implications on future innovation roadmap for desalination. Desalination 2015, 368, 181-192. [CrossRef]

2. Elimelech, M.; Phillip, W. The future of seawater desalination: Energy, technology, and the environment. Science 2011, 333, 712-717. [CrossRef] [PubMed]

3. Darling, S.B. Perspective: Interfacial materials at the interface of energy and water. J. Appl. Phys. 2018, 124, 030901. [CrossRef]

4. Elma, M.; Yacou, C.; Wang, D.K.; Smart, S.; Diniz da Costa, J.C. Microporous silica based membranes for desalination. Water 2012, 4, 629-649. [CrossRef]

5. Shannon, M.A.; Bohn, P.W.; Elimelech, M.; Georgiadis, J.G.; Marĩas, B.J.; Mayes, A.M. Science and technology for water purification in the coming decades. Nature 2008, 452, 301-310. [CrossRef] [PubMed]

6. Greenlee, L.F.; Lawler, D.F.; Freeman, B.D.; Marrot, B.; Moulin, P. Reverse osmosis desalination: Water sources, technology, and today's challenges. Water Res. 2009, 43, 2317-2348. [CrossRef] [PubMed]

7. Form No. 609-00519-1206, FILMTEC NF270 Nanofiltration Elements for Commercial Systems; The Dow Chemical Company: Midlan, MI, USA; Available online: https://www.dupont.com/products/filmtecnf2704040.html (accessed on 22 September 2019).

8. Form No. 609-00379-0503, FILMTEC Membranes, Nanofiltration Produces Sparkling Clean Water for Swedish Resort Community; The Dow Chemical Company: Midlan, MI, USA; Available online: https://www. dupont.com/content/dam/dupont/amer/us/en/water-solutions/general/documents/609-00379.pdf (accessed on 22 September 2019).

9. Lee, K.P.; Arnot, T.C.; Mattia, D. A review of reverse osmosis membrane materials for desalination-Development to date and future potential. J. Memb. Sci. 2011, 370, 1-22. [CrossRef]

10. Farahbakhsh, K.; Svrcek, C.; Guest, R.K.; Smith, D.W. A review of the impact of chemical pretreatment on low-pressure water treatment membranes. J. Environ. Eng. Sci. 2004, 4, 237-253. [CrossRef]

11. Tsuru, T. Inorganic porous membranes for liquid phase separation. Sep. Purif. Methods. 2001, 30, 191-220. [CrossRef]

12. Lin, Y.S. Microporous and dense inorganic membranes: Current status and prospective. Sep. Purif. Technol. 2001, 25, 39-55. [CrossRef]

13. Farsi, A.; Malvache, C.; De Bartolis, O.; Magnacca, G.; Kristensen, P.K.; Christensen, M.L.; Boffa, V. Design and fabrication of silica-based nanofiltration membranes for water desalination and detoxification. Microporous Mesoporous Mater. 2017, 237, 117-126. [CrossRef]

14. Wijaya, S.; Duke, M.C.; Diniz da Costa, J.C. Carbonised template silica membranes for desalination. Desalination 2009, 236, 291-298. [CrossRef] 
15. Boffa, V.; Parmeggiani, L.; Nielsen, A.H.; Magnacca, G. Hydrophilicity and surface heterogeneity of $\mathrm{TiO}_{2}$-doped silica materials for membrane applications. Microporous Mesoporous Mater. 2016, 221, 81-90. [CrossRef]

16. Fotou, G.P.; Lin, Y.S.; Pratsinis, S.E. Hydrothermal stability of pure and modified microporous silica membranes. J. Mater. Sci. 1995, 30, 2803-2808. [CrossRef]

17. Boffa, V.; Blank, D.H.A.; ten Elshof, J.E. Hydrothermal stability of microporous silica and niobia-silica membranes. J. Memb. Sci. 2008, 319, 256-263. [CrossRef]

18. Waldman, R.Z.; Choudhury, D.; Mandia, D.J.; Elam, J.W.; Nealey, P.F.; Martinson, A.B.F.; Darling, S.B. Sequential Infiltration Synthesis of $\mathrm{Al}_{2} \mathrm{O}_{3}$ in Polyethersulfone Membranes. JOM 2019, 71, 212-223. [CrossRef]

19. Lin, C.X.C.; Ding, L.P.; Smart, S.; Diniz da Costa, J.C. Cobalt oxide silica membranes for desalination. J. Colloid Interface Sci. 2012, 368, 70-76. [CrossRef] [PubMed]

20. Boffa, V.; Magnacca, G.; Jørgensen, L.B.; Wehner, A.; Dörnhöfer, A.; Yue, Y. Toward the effective design of steam-stable silica-based membranes. Microporous Mesoporous Mater. 2013, 179, 242-249. [CrossRef]

21. Gu, Y.; Hacarlioglu, P.; Oyama, S.T. Hydrothermally stable silica-alumina composite membranes for hydrogen separation. J. Membr. Sci. 2008, 310, 28-37. [CrossRef]

22. Li, L.; Liu, N.; McPherson, B.; Lee, R. Enhanced water permeation of reverse osmosis through MFI-type zeolite membranes with high aluminum contents. Ind. Eng. Chem. Res. 2007, 46, 1584-1589. [CrossRef]

23. Goh, P.S.; Ismail, A.F. A review on inorganic membranes for desalination and wastewater treatment. Desalination 2017, 434, 60-80. [CrossRef]

24. Wen, J.; Wilkes, G.L. Organic/inorganic hybrid network materials by the sol-gel approach. Chem. Mater. 1996, 8, 1667-1681. [CrossRef]

25. De Lange, R.S.A.; Kumar, K.N.P.; Hekkink, J.H.A.; van de Velde, G.M.H.; Keizer, K.; Burggraaf, A.J.; Dokter, W.H.; van Garderen, H.F.; Beelen, T.P.M. Microporous $\mathrm{SiO}_{2}$ and $\mathrm{SiO}_{2} / \mathrm{MO}_{\mathbf{x}}(\mathrm{M}=\mathrm{Ti}, \mathrm{Zr}$, $\mathrm{Al})$ for ceramic membrane applications: A microstructural study of the sol-stage and the consolidated state. J. Sol.-Gel Sci. Technol. 1994, 2, 489-495. [CrossRef]

26. Boffa, V.; Castricum, H.L.; Garcia, R.; Schmuhl, R.; Petukhov, A.V.; Blank, D.H.A.; Ten Elshof, J.E. Structure and growth of polymeric niobia-silica mixed-oxide sols for microporous molecular sieving membranes: A saxs study. Chem. Mater. 2009, 21, 1822-1828. [CrossRef]

27. Samiey, B.; Cheng, C.H.; Wu, J. Effects of surfactants on the rate of chemical reactions. J. Chem. 2014, 2014, 564-567. [CrossRef]

28. Mege, S.; Vereist, M.; Lecante, P.; Perez, E.; Ansart, F.; Savariault, J.M. Surfactant effects in vanadium alkoxide derived gels. J. Non. Cryst. Solids 1998, 238, 37-44. [CrossRef]

29. Liu, S.; Boffa, V.; Yang, D.; Fan, Z.; Meng, F.; Yue, Y. Clarifying the gel-to-glass transformation in $\mathrm{Al}_{2} \mathrm{O}_{3}-\mathrm{SiO}_{2}$ systems. J. Non. Cryst. Solids 2018, 492, 77-83. [CrossRef]

30. Olivier, J.P. Modeling physical adsorption on porous and nonporous solids using density functional theory. J. Porous Mater. 1995, 2, 9-17. [CrossRef]

31. Farsi, A.; Boffa, V.; Qureshi, H.F.; Nijmeijer, A.; Winnubst, L.; Christensen, M.L. Modeling water flux and salt rejection of mesoporous $\gamma$-alumina and microporous organosilica membranes. J. Memb. Sci. 2014, 470, 307-315. [CrossRef]

32. Sing, K.S.W.; Everett, D.H.; Haul, R.A.W.; Moscou, L.; Pierotti, R.S.; Rouquerol, J. Siemieniewska, Reporting physisorption data for gas/solid systems with special reference to the determination of surface area and porosity. Pure Appl. Chem. 1985, 57, 603-619. [CrossRef]

33. Strawbridge, I.; James, P.F. The factors affecting the thickness of sol-gel derived silica coatings prepared by dipping. J. Non. Cryst. Solids 1986, 86, 381-393. [CrossRef]

34. Brinker, C.J.; Scherer, G.W. Sol-Gel Science: The Physics and Chemistry of Sol-Gel Processing, 2nd ed.; Academic Press: San Diego, CA, USA, 1990; pp. 788-797.

35. Zhu, B.; Myat, D.T.; Shin, J.; Na, Y.; Moon, I.; Connor, G.; Maeda, S.; Morris, G.; Gray, S.; Duke, M. Application of robust MFI-type zeolite membrane for desalination of saline wastewater. J. Memb. Sci. 2015, 475, 167-174. [CrossRef]

(C) 2019 by the authors. Licensee MDPI, Basel, Switzerland. This article is an open access article distributed under the terms and conditions of the Creative Commons Attribution (CC BY) license (http://creativecommons.org/licenses/by/4.0/). 